\title{
Ácido Sórbico e Câncer Gastrointestinal: uma Revisão Integrativa
}

\author{
Sorbic Acid and Gastrointestinal Cancer: an Integrative Review
}

\author{
Renata Carmo de Assis*a; Thalyta Vasconcelos Pacheco ${ }^{\mathrm{a}}$; Ana Carolina Marinho Ferreira ${ }^{\mathrm{b}}$; Tayane Carneiro Cruz ${ }^{\mathrm{a}}$; \\ Ana Bárbara Muniz Araújo ${ }^{\text {a }}$ Carla Soraya Costa Maia ${ }^{a}$
}

${ }^{a}$ Universidade Estadual do Ceará. CE, Brasil.

'Instituto Superior de Tecnologia Aplicada- Inta-Uninta, CE, Brasil.

*E-mail: renata.carmo@uece.br

\begin{abstract}
Resumo
A industrialização de alimentos resultou em um novo modelo alimentar altamente processado. O consumo de alimentos industrializados, aumenta a ingestão de aditivos alimentares, que possuem a função de preservação das características do alimento bem como melhorias nas propriedades sensoriais. Entretanto alguns estudos demonstram que se adicionados em quantidade elevadas para consumo podem levar a toxicidade. Assim, o objetivo do estudo foi revisar dados publicados que relacionam o uso do aditivo químico sorbato de potássio como conservante alimentar com o desenvolvimento de câncer gastrointestinal. Trata-se de uma revisão integrativa seguindo seis etapas distintas (1. Elaboração da pergunta norteadora; 2. Busca ou amostragem na literatura; 3 . Coleta de dados; 4. Análise crítica dos estudos incluídos; 5. Discussão dos resultados e 6. Apresentação da revisão integrativa). Foi realizada entre os meses de março e abril de 2019 nas bases de dados: Periódicos CAPES, Pubmed, Biblioteca virtual Unicamp e Science Direct. Os descritores principais utilizados foram: "Potassium sorbate" e "Sorbic acid", combinados com os descritores, "gastrointestinal neoplasia", "Cancer of gastrointestinal tract" e "Neoplasia". Após leitura dos títulos e resumos, foram incluídos oito artigos e, após leitura destes, permaneceram seis artigos. Diante dos artigos encontrados é possível afirmar que o ácido sórbico e o sorbato de potássio tem baixa relação com o desenvolvimento de câncer gastrointestinal.
\end{abstract}

Palavras-chave: Aditivos Alimentares. Ácido Sórbico. Neoplasias Gastrointestinais

\begin{abstract}
Food industrialization has resulted in a new highly processed food model. The consumption of industrialized food increases the food additives intake, which have the function of preserving the food characteristics as well as improving sensory properties. However, some studies show that if added in high amounts for consumption they can lead to toxicity. Thus, the objective of the study was to review published data that relate the use of the chemical additive potassium sorbate as a food preservative with the development of gastrointestinal cancer. It is an integrative review following six distinct steps (1. Preparation of the guiding question; 2. Searching or sampling in the literature; 3. Data collection; 4. Critical analysis of the studies included; 5. Discussion of the results and 6. Presentation of the integrative review). It was held between March and April 2019 in the databases: CAPES Periodicals, Pubmed, Virtual Library Unicamp and Science Direct. The main descriptors used were: "Potassium sorbate" and "Sorbic acid", combined with the descriptors "gastrointestinal neoplasia", "Gastrointestinal tract cancer" and "Neoplasia". After reading the titles and abstracts, eight articles were included and, after reading them, six articles remained. It is possible to affirm that sorbic acid and potassium sorbate have a low relation with the development of gastrointestinal cancer.
\end{abstract}

Keywords: Food Additives. Sorbic Acid. Gastrointestinal Neoplasms.

\section{Introdução}

Nos últimos anos, o Brasil passou por transformações no processo saúde/doença, das quais, são observadas alterações na qualidade e na quantidade da dieta, associadas a mudanças no estilo de vida, nas condições econômicas, sociais e demográficas (BRASIL, 2014).

A industrialização de alimentos, transformou a alimentação, dando lugar a uma alimentação prática e rápida, trazendo como consequências um novo modelo alimentar altamente processado e massificado (CONTE, 2016).

O grande consumo de alimentos industrializados, aumenta também a ingestão de aditivos alimentares. Que por um lado, trouxe a vantagem da preservação das características do alimento por tempo prolongado, bem como melhorias nas propriedades sensoriais, entre outros benefícios. No entanto, o seu consumo pode propiciar aos indivíduos alguns males à saúde como alergia, aumento de hiperatividade, câncer, entre outros (ALBUQUERQUE et al., 2012).

Dentre os aditivos alimentares, na classe dos conservantes, o ácido sórbico e seus sais de potássio e sódio, são amplamente utilizados, entretanto alguns estudos em animais demonstram que se adicionados em quantidade elevadas para consumo podem levar a toxicidade materna e fetal, sendo observados vários efeitos adversos, como diminuição no peso corporal médio, prejuízos no desenvolvimento físico e funcional e diminuição da distância anogenital em filhotes (EFSA, 2015).

Devido ao elevado consumo, deve haver uma preocupação quanto a sua relação com o desenvolvimento de câncer gastrointestinal, uma vez que é a via metabólica desses aditivos. O câncer gastrointestinal é um dos principais contribuintes para a morbidade e mortalidade relacionadas ao câncer em todo o mundo. Sendo o câncer de estômago o quinto diagnóstico mais 
frequente de câncer e a terceira principal causa de morte. $\mathrm{O}$ câncer de fígado é o sexto mais diagnosticado e a quarta principal causa de morte por câncer em todo mundo em 2018. E, câncer colorretal ocupa a segunda colocação em termos de mortalidade e o terceiro em termos de incidência (BRAY et al., 2018).

O Generally Recognized as Safe - GRAS, que é a designação da Food and Drug Administration (FDA) para determinar se produtos químicos ou substâncias adicionadas a alimentos são consideradas seguras, reconhece o ácido sórbico, sorbato de potássio e sorbato de sódio como geralmente seguros, quando usados em conformidade com as boas práticas de fabricação (FDA, 2019). A Agência Nacional de Vigilância Sanitária ANVISA, permite seu uso, dentro dos limites e aplicações estabelecidos para cada categoria de alimentos (BRASIL, 1998).

O Joint FAO/WHO Expert Committee on Food Additives (JECFA), avaliou o ácido sórbico e seus sais em 1961, 1965 e 1973, determinando uma ingestão diária aceitável (IDA) de 25 $\mathrm{mg} / \mathrm{kg}$ de peso corporal/dia (WHO, 1974).

Sendo esse valor mantido pelo Scientific Committee on Food (SCF), em 1994 (SCF, 1996). Em novo estudo, a European Food Safety Authority (EFSA) reavaliou o ácido sórbico e seus sais e determinou uma IDA temporária de $3 \mathrm{mg} / \mathrm{kg}$ de peso corporal/ dia para o ácido sórbico e o sorbato de potássio, e recomendou a descontinuação do uso do sorbato de sódio, uma vez que apresenta risco a saúde (EFSA, 2015).

Tais aditivos alimentares estão presentes em alimentos amplamente consumidos pela população, como: produtos de panificação, lácteos, frutas secas, frutas e legumes em conserva, temperos e condimentos, alimentos dietéticos para fins medicinais e bebidas aromatizadas e alcoólicas (EFSA, 2015). Externando a importância de conhecer seus riscos a saúde.

Dessa forma, o presente estudo tem como finalidade revisar dados publicados que relacionam o uso do aditivo alimentar ácido sórbico como conservante alimentar com o desenvolvimento de câncer gastrointestinal.

\section{Desenvolvimento}

\subsection{Metodologia}

O presente estudo trata-se de um revisão integrativa seguindo o que preconiza Mendes et al. (2008), que é composta por seis etapas distintas: 1) elaboração da pergunta norteadora; 2) busca ou amostragem na literatura; 3) coleta de dados; 4) análise crítica dos estudos incluídos; 5) discussão dos resultados e 6) apresentação da revisão integrativa.

O estudo iniciou com a pergunta norteadora: "o aditivo alimentar ácido sórbico utilizado com finalidade de aumentar o tempo de prateleira dos alimentos processados tem relação com câncer no sistema gastrointestinal em seus usuários?”

A busca em base de dados foi realizada entre os meses de março e abril de 2019 nas seguintes bases de dados: Periódicos CAPES, Pubmed, Biblioteca virtual UNICAMP e Science Direct, não tendo sido demarcado período restrito de publicações.

Foram utilizados descritores principais em inglês: "Potassium sorbate" e "Sorbic acid", combinados com outros descritores, "gastrointestinal neoplasm", "Cancer of gastrointestinal tract" e "Neoplasm".

No primeiro momento, houve leitura breve dos títulos e resumos dos trabalhos científicos encontrados com as combinações dos descritores, havendo assim a seleção das pesquisas que contemplavam o assunto da pergunta norteadora. Os estudos escolhidos foram tabulados a fim de esquematizar todo o processo de busca, visualizando quantos estudos foram incluídos ou excluídos considerando cada critério prédeterminado.

Em seguida, foram coletados os dados dos estudos selecionados para a análise por meio de um instrumento de coleta que apresenta a referência, ano, país, amostra utilizada, veículo e considerações dos autores. Sendo, a amostra final organizada por ordem decrescente do ano de publicação.

A última etapa da revisão consistiu na apresentação dos resultados, onde as informações de cada estudo que se apresentaram mais relevantes à revisão foram expostas de modo descritivo e contextualizado. Os dados foram organizados sucinta e individualmente para facilitar a análise crítica da amostra e as conclusões prévias obtidas a partir de cada leitura.

\subsection{Resultados e Discussão}

$\mathrm{Na}$ presente revisão integrativa, após leitura dos títulos e resumos, foram incluídos oito artigos e após leitura destes, permaneceram seis artigos. O fluxograma que demonstra a escolha de tais artigos pode ser observado na Figura 01.

Diante da busca de artigos nas bases de dados selecionadas, observa-se a escassez de estudos recentes publicados sobre a relação do ácido sórbico com câncer gastrointestinal. O que possivelmente se justifique, devido ao uso na indústria alimentícia ter por obrigação, que respeitar os limites de consumo estabelecidos pelo GRAS e ANVISA.

Figura 1 - Resultados da pesquisa na literatura referente à busca por estudos em diferentes bases de dados

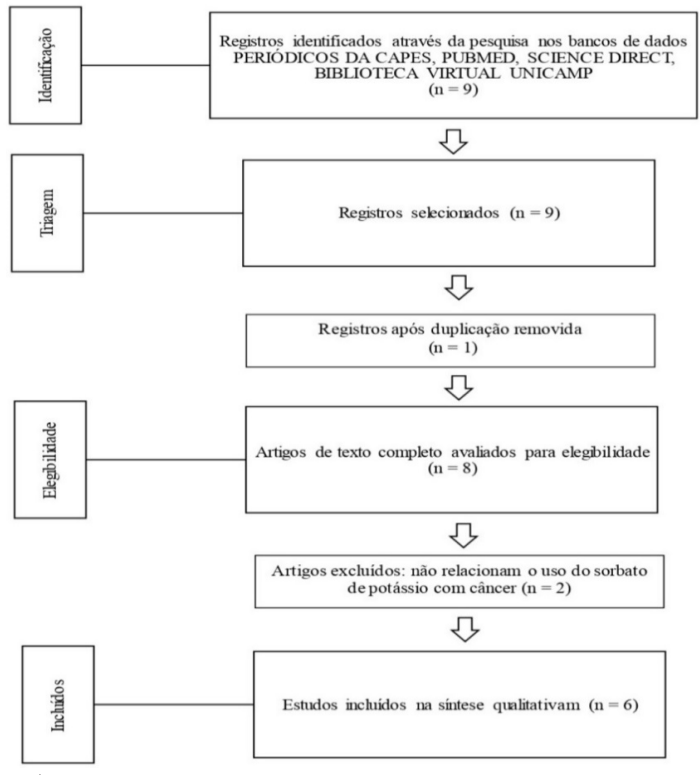

Fonte: Autores. 
O Quadro 1 expõe um panorama geral das seis publicações metodológicos e resultados dos artigos elencados.

selecionadas, destacando a caracterização, aspectos

Quadro 1 - Dados referentes aos autores, ano de publicação, país onde o estudo foi desenvolvido, amostra utilizada nos experimentos e as principais considerações do estudo

\begin{tabular}{|c|c|c|c|c|c|}
\hline Autor & Ano & País & Amostra Utilizada & Veículo & Considerações dos Autores \\
\hline $\begin{array}{l}\text { Dickens } \\
\text { et al. }\end{array}$ & 1968 & Inglaterra & $\begin{array}{l}\text { (a) } 2 \mathrm{mg} \text { de ácido sórbico com } 0,5 \mathrm{ml} \\
\text { de água } \\
\text { (b) } 2 \mathrm{mg} \text { de ácido sórbico com } 0,5 \mathrm{ml} \\
\text { de óleo de amendoim } \\
\text { (c) } 2 \mathrm{mg} \text { de sorbato de potássio com } \\
0,5 \mathrm{ml} \text { de água }+1 \% \text { de sorbato de } \\
\text { potássio na dieta e } 0,3 \% \text { na água } \\
\text { (d) } 2 \mathrm{mg} \text { de sorbato de potássio com } \\
0,5 \mathrm{ml} \text { de água }\end{array}$ & Ratos Wistar & $\begin{array}{l}\text { Amostra (a) foi responsável por induzir } \\
\text { fibrossarcoma, em } 2 \text { de } 6 \text { ratos. Nenhuma } \\
\text { outra preparação administrada por injeção } \\
\text { subcutânea foi responsável por induzir } \\
\text { tumores locais. As amostras de sorbato de } \\
\text { potássio também não induziram tumores } \\
\text { quando administrados por via oral durante } \\
\text { todo o experimento. }\end{array}$ \\
\hline $\begin{array}{l}\text { Mason et } \\
\text { al. }\end{array}$ & 1976 & Inglaterra & $\begin{array}{l}\text { (a) } 1,2 \% \text { de ácido sórbico na dieta } \\
\text { (b) } 1,2 \% \text { de ácido sórbico com } \\
\text { 100ppm de ácido parassorbico na } \\
\text { dieta }\end{array}$ & $\begin{array}{l}\text { Ratos de uma } \\
\text { cepa derivada } \\
\text { de Wistar }\end{array}$ & $\begin{array}{l}\text { A inclusão do ácido para sórbico não teve } \\
\text { efeito significativo sobre o ganho de peso } \\
\text { corporal, ingestão de alimentos ou água, } \\
\text { exames hematológicos, testes de função renal, } \\
\text { análises séricas ou os achados do exame } \\
\text { histopatológico, incluindo a incidência de } \\
\text { tumores. }\end{array}$ \\
\hline $\begin{array}{l}\text { Daoud e } \\
\text { Griffin }\end{array}$ & 1980 & U.S.A. & $\begin{array}{l}0,05 \% \text { de } 3 \text { '-metil-4- } \\
\text { dimetilainoazobenzeno (3'-MeDAB) } \\
\text { suplementada com } 1 \% \text { ou } 2 \% \text { de } \\
\text { ácido sórbico na dieta. }\end{array}$ & $\begin{array}{c}\text { Ratos Sprague- } \\
\text { Dawley }\end{array}$ & $\begin{array}{l}\text { O ácido sórbico não exerceu nenhum efeito } \\
\text { protetor contra a hepatocarcinogênese } \\
\text { do } 3 \text { '-metil-4-dimetilaminoazobenzeno } \\
\text { (3'-MeDAB) (azocorante). }\end{array}$ \\
\hline $\begin{array}{l}\text { Furihata } \\
\text { et al. }\end{array}$ & 1989 & Japão & $\begin{array}{l}0 ; 0,6 ; 1,2 ; 1,7 \text { ou } 2,3 \mathrm{~g} / \mathrm{kg} \text { de sorbato } \\
\text { de sódio por intubação gástrica }\end{array}$ & Ratos F344 & $\begin{array}{l}\text { Aumentos de até } 100 \text { vezes na atividade } \\
\text { da ornitina descarboxilase (ODC) foram } \\
\text { observados após a administração de sorbato } \\
\text { de sódio. Este aditivo alimentar pode ter } \\
\text { atividades promotoras de tumor na mucosa } \\
\text { pilórica de ratos. }\end{array}$ \\
\hline $\begin{array}{l}\text { Sasaki et } \\
\text { al. }\end{array}$ & 2002 & Japão & $\begin{array}{l}>2000 \mathrm{mg} / \mathrm{kg} \text { de ácido sórbico ou } \\
\text { sorbato de potássio }\end{array}$ & $\begin{array}{l}\text { Camundongos } \\
\text { ddY }\end{array}$ & $\begin{array}{l}\text { Ácido sórbico e seu sal de potássio não } \\
\text { produziram aumento significativo do dano } \\
\text { ao DNA em qualquer dos órgãos estudados } \\
\text { (estômago glandular, cólon, fígado, rim, } \\
\text { bexiga urinária, pulmão, cérebro e medula } \\
\text { óssea). }\end{array}$ \\
\hline $\begin{array}{l}\text { Winkler } \\
\text { et al. }\end{array}$ & 2006 & Austria & $\begin{array}{l}1 \mathrm{mM} ; 10 \mathrm{mM} \text { ou } 50 \mathrm{mM} \text { de ácido } \\
\text { sórbico }\end{array}$ & $\begin{array}{l}\text { Células } \\
\text { mononucleares } \\
\text { de sangue } \\
\text { periférico } \\
\text { humano } \\
\text { (PBMC) }\end{array}$ & $\begin{array}{l}\text { Os dados demonstram uma influência } \\
\text { supressora do ácido sórbico na resposta imune } \\
\text { do tipo Th1 ativada. } \\
\text { O sistema Thlé ativado em casos como } \\
\text { infecções por vírus, síndromes autoimunes ou } \\
\text { câncer. }\end{array}$ \\
\hline
\end{tabular}

Fonte: Dados da pesquisa.

Da análise dos conteúdos dos artigos incluídos, contemplamos diferentes objetivos e metodologias, no qual, cinco trabalhos realizaram suas experiências in vivo, utilizando animais em laboratórios e apenas um trabalho foi realizado in vitro com células de sangue humano.

Para os trabalhos in vivo, todos foram realizados com monitoramento do meio em que o animal estava exposto, alimentação e processo metodológico no qual foram submetidos.

Em estudo com ratos machos Wistar divididos em grupos de seis ou doze animais por um período de 56 a 60 semanas, administraram ácido sórbico ou sorbato de potássio por via subcutânea ou via oral, dependendo do grupo. Ao final do estudo avaliaram se houve desenvolvimento de tumores hepáticos. Nos grupos onde a administração aconteceu por via oral, não foram encontrados casos de tumores hepáticos, mas em um dos grupos onde a administração foi subcutânea tendo água como solvente, surgiram fibrossarcomas nos locais de aplicação (DICKENS; JONES; WAYNFORTH, 1968).

Mason et al. (1976), em seu estudo, objetivou analisar as consequências sobre a saúde de ratos após a ingestão de dieta contendo ácido sórbico. Utilizando ratos de uma cepa derivada de Wistar, estes foram alimentados com uma dieta básica de Spillers contendo 1,2\% ácido sórbico (grupo AS, composto por 24 machos e 24 fêmeas), com média de ingestão diária de $0,41-0,45 \mathrm{mg} / \mathrm{kg}$ no sexo masculino e 0,62-0,63 mg/kg no sexo feminino, que foram acompanhados por um período de dois anos. Como resultados não foram encontrados componentes anormais na urina ou alterações nos testes renais, análises séricas ou hematológicas, nos achados do exame histopatológico, incluindo a incidência de tumores.

Daoud e Griffin (1980) estudaram o efeito protetor contra 
a hepatocarcinogênese de algumas substâncias, dentre elas o sorbato de potássio. Para o estudo foram utilizados ratos albinos machos da linhagem Sprague - Dawley, que tiveram o câncer hepático induzido por uma dieta contendo $0,05 \%$ de 3'-metil-4-dimetilaminoazobenzeno (3'-MeDAB) (corante azo) durante nove semanas, sendo o ácido sórbico utilizado como suplemento em um dos grupos. O ácido sórbico não exerceu efeito protetor contra a hepatocarcinogênese, tendo incidência de $100 \%$ de tumores hepáticos neste grupo.

Furihata et al. (1989) analisaram a atividade de variados sais de aditivos alimentares como promotores de tumores na mucosa estomacal de ratos machos F344 após administração por intubação gástrica. Um grupo recebeu 0,5 a $1 \mathrm{ml}$ de solução aquosa contendo 8,92 - $17,1 \mathrm{mmol} / \mathrm{kg}$ de sorbato de sódio (sal do ácido sórbico) e obtendo como resultado, oito horas após a administração do sal, o aumento de 100 vezes da atividade da ornitina descarboxilase (ODC) que é considerada um marcador de atividade de iniciação tumoral. Sugerindo assim, sua possível promoção da atividade tumoral na carcinogênese do estômago.

Sasaki et al. (2002) avaliaram nove diferentes aditivos alimentares e sua ação glandular sobre os órgãos estômago, cólon, fígado, rim, bexiga urinária, pulmão, cérebro e medula óssea, 3 e 24 horas após a administração. Como espécie de rato foi escolhido o DDY machos, e administrado via oral $2000 \mathrm{mg} / \mathrm{kg}$ de ácido sórbico, 3 ou 24 horas após, os ratos foram sacrificados e realizada a necropsia dos oitos órgãos analisados, ocorrendo a avaliação de alterações no tamanho, cor e textura. Como resultado o ácido sórbico e seus sais de potássio não produziram significativo dano ao DNA em qualquer um dos órgãos estudados.

Winkler et al. (2006) avaliaram a ação do ácido sórbico em células mononucleares do sangue periférico humano (PBMC) in vitro, diante de uma resposta imune do tipo Th1 induzida. Essa resposta imune acontece diante de infecções como vírus, síndromes auto-imunes ou câncer e leva a geração de espécies reativas de oxigênio (ERO). Após um período de incubação de 48h, o ácido sórbico suprimiu a resposta imune.

Diante dos resultados encontrados nos artigos elencados, é possível dizer que o ácido sórbico e o sorbato de potássio apresentam baixa toxicidade como promotores de câncer gastrointestinal, uma vez que só foi observada essa relação em estudo de Furihata et al. (1989), resultado esse que pode ser explicado pelo estudo ter feito uso do sorbato de sódio, uma vez que esse sal do ácido sórbico apresenta dados positivos de genotoxicidade, não sendo seu uso permitido em diversos países como demonstrado na literatura científica. Ressaltando que seu uso é liberado no Brasil (EFSA, 2015).

Em um estudo de revisão afirma que a toxicidade do ácido sórbico é muito baixa em mamíferos, justificando assim seu uso na indústria de alimentos, contanto que sejam respeitados os limites das boas práticas de fabricação de cada grupo alimentar. E justifica sua baixa toxicidade, devido a sua metabolização ocorrer rapidamente por caminhos semelhantes a outros ácidos graxos. O que corrobora com os resultados encontrados na presente revisão (WALKER, 1990).

Exceder o limite de consumo estabelecido pode levar a genotoxicidade de acordo com a ESFA (2015), que por esse motivo diminuiu a IDA de $25 \mathrm{mg} / \mathrm{kg}$ de peso corporal/dia para $3 \mathrm{mg} / \mathrm{kg}$ de peso corporal/dia temporariamente até que mais estudos sejam feitos. Além de mostrar que os principais alimentos que contribuem para o consumo desse aditivo são pães, produtos finos de panificação e bebidas aromatizadas.

É importante ressaltar que a ANVISA estabelece um limite de aplicação do sorbato de potássio para cada grupo alimentar, e que ao longo do dia não devem exceder a IDA. $\mathrm{O}$ que externa a necessidade de estudos que quantifiquem seu consumo na população brasileira, uma vez que os alimentos que mais contribuem para o seu consumo são amplamente consumidos.

\section{Conclusão}

Diante do exposto, é possível dizer que o ácido sórbico e o sorbato de potássio tem baixa relação com a desenvolvimento de câncer gastrointestinal, contudo o sorbato de sódio apresenta dados positivos de genotoxicidade, sendo seu desuso recomendado na União Europeia.

Recomenda-se, respeitar os limites estabelecidos de aplicação, de acordo com as boas práticas de fabricação, e os limites de consumo, uma vez que o uso acima desse limite não é recomendado para consumo humano.

Assim como propor, estudos em bases de dados com o intuito de calcular a quantidade consumida pela população brasileira, correlacionando com a recomendação conhecida.

\section{Referências}

ALBUQUERQUE, M. V., SANTOS, A. S.; CERQUEIRA, N. T. V.; SILVA, J. A. Educação alimentar: uma proposta de redução do consumo de aditivos alimentares. Revista Quím. Nova, v.34, n.2, p.51-57, 2012.

BRASIL. Ministério da Saúde. Agência Nacional de Vigilância Sanitária. Legislação. Portarias. Portaria $n^{\circ}$. 1003, de 11 de dezembro de 1998. Categoria de alimentos para efeito do emprego de aditivos. Disponível em: htpp://www.anvisa.gov.br/ legis/portarias/1003_98.htm. Acesso: 14 mar. 2020.

BRASIL. Ministério da Saúde, Secretaria de Atenção à Saúde, Departamento de Atenção Básica. Guia alimentar para a população brasileira. Brasília: MS, 2014.

BRAY, F. et al. Global cancer statistics 2018: GLOBOCAN estimates of incidence and mortality worldwide for 36 cancers in 185 countries. CA Cancer J. Clin., v.68, n.6, p. 394-424, 2018. doi: $10.3322 /$ caac. 21492 .

CONTE, F. A. Efeitos do consumo de aditivos químicos alimentares na saúde humana. Rev. Espaço Acadêm., v.16, n.181, p.69-81, 2016.

DAOUD, A.H.; GRIFFIN, A.C. Effect of retinoic acid, butylated hydroxytoluene, selenium, and sorbic acid on azo-dye hepatocarcinogenesis. Cancer Lett., v.9, n.4, p.299-304, 1980. doi: 10.1016/0304-3835(80)90021-x.

DICKENS, F.; JONES, H.E.H.; WAYNFORTH, H.B. Further tests on the carcinogenicity of sorbic acid in the rat. Bras. J. 
Cancer., v.22, n.4, p.762-768, 1968. doi:10.1038/bjc.1968.90.

EFSA ANS Panel (EFSA panel on food additives and nutrient sources added to food). Scientific opinion on the re-evaluation of sorbic acid (E200), potassium sorbate (E202) and calcium sorbate (E203) as food additives. EFSA J., v.13, n.6, p.4144, 2015.

FDA - Food and Drug Administration. Code of Federal Regulations, 21 CFR 182. Title 21-Food and Drugs, vol. 3. Chapter I - Food and Drug Administration, Department of Health and Human Services. Part 182 - Substances Generally Recognized as Safe. Subpart D-Chemical Preservatives, $\$ 182.3640$ Potassium sorbate. 2019. Disponível em: http:// www1.inca.gov.br/estimativa/2018/estimativa-2018.pdf. Acesso: 29 set. 2019.

FURIHATA, C. et al. Various sodium salts, potassium salts, a calcium salt and an ammonium salt induced ornithine decarboxylase and stimulated DNA synthesis in rat stomach mucosa. Jpn. J. Cancer Res., v.80, n.5, p.424-429, 1989. doi: 10.1111/j.1349-7006.1989.tb02331.x.

MASON, P.L. et al. Long-term toxicity of parasorbic acid in rats Food Cosmet. Toxicol., v.14, n.5, p.387-394, 1976. doi: 10.1016/ s0015-6264(76)80174-5.

MENDES, K.D.S.; SILVEIRA, R.C.C.P.; GALVÃO, C.M. Revisão integrativa: método de pesquisa para a incorporação de evidências na saúde e na enfermagem. Texto Contexto Enferm., v.17, n.4, p.758-764, 2008. doi: https://doi.org/10.1590/S010407072008000400018 .

SASAKI, Y.F. et al. The comet assay with 8 mouse organs: results with 39 currently used food additives. Mutat Res., v.519, n.1/2, p.103-119, 2002. doi: 10.1016/s1383-5718(02)00128-6.

SCF - Scientific Committee for Food. Opinion on sorbic acid and its calcium and potassium salts Reports of the Scientific. In: Committee for Food (Thirtyfifth series). Luxembourg: Office for Official Publications of the European Communities, 1996. p.1922.

WALKER, R. Toxicology of sorbic acid and sorbates. Food Addit. Contam. A., v.7, n.5, p.671-676, 1990. doi: $10.1080 / 02652039009373932$.

WHO - World Health Organization. Toxicological evaluation of some food additives including anticaking agents, antimicrobials, antioxidants, emulsifiers and thickening agents. Seventeenth report of the Joint FAO/WHO Expert Committee on Food Additives. WHO Food Additive Series No 5, 1974. Disponível em: http://www.inchem.org/documents/jecfa/jecmono/v05je01. htm. Acesso: 15 jun. 2020.

WINKLER, C. et al. Food preservatives sodium sulfite and sorbic acid suppress mitogen-stimulated peripheral blood mononuclear cells. Food Chem Toxicol., v.44, n.12, p.2003-2007, 2006. doi: 10.1016/j.fct.2006.06.019. 